\title{
Electroplated thick-film cobalt platinum permanent magnets
}

\author{
Ololade D. Oniku, Bin Qi and David P. Arnold \\ Interdisciplinary Microsystems Group, Dept. of Electrical and Computer Engineering, \\ University of Florida, Gainesville, FL 32611, USA \\ Email: darnold@ufl.edu
}

\begin{abstract}
The material and magnetic properties of multi-micron-thick (up to $6 \mathrm{~m}$ ) $\mathrm{L}_{0} \mathrm{CoPt}$ magnetic films electroplated onto silicon substrates are investigated as candidate materials for integration in silicon-based microsystems. The influence of various process confitions on the structure and magnetic properties of electroplated CoPt thick-films is studied in order to better understand the complex process/structure/property relationships associated with the electroplated films. Process variables studied here include different seed layers, electroplating current densities (ranging from $25-200 \mathrm{~mA} / \mathrm{cm}^{2}$ ), deposition times (up to $60 \mathrm{~min}$ ), and post-deposition annealing times and temperatures. Analyses include film morphology, film thickness, composition, surface roughness, grain size, phase volume fractions, and $\mathrm{L}_{0}$ ordering parameter. Key correlations are found relating process and structure variations to the extrinsic magnetic properties (remanence, coercivity, squareness, and energy product). Strong hard magnetic properties $\left(\mathrm{B}_{\mathrm{r}} \sim 0.8 \mathrm{~T}, \mathrm{H}_{\mathrm{ci}} \sim 800\right.$ $\mathrm{kA} / \mathrm{m}$, squareness close to 0.9 , and $\mathrm{BH}_{\max }$ of $100 \mathrm{~kJ} / \mathrm{m}^{3}$ ) are obtained for films deposited on $\mathrm{Si} / \mathrm{TiN} / \mathrm{Ti} / \mathrm{Cu}$ at current densities of $100 \mathrm{~mA} / \mathrm{cm}^{2}, \mathrm{pH}$ of 7 , and subsequently annealed at $675^{\circ} \mathrm{C}$ for $30 \mathrm{~min}$.
\end{abstract}

Keywords: CoPt, electroplating, permanent magnets, thick films

\section{Introduction}

Over the last few decades, high-energy-density permanent magnets have engendered significant performance advancements in motors/generators, electromechanical transducers, biomedical devices, scientific instruments, and many consumer products that benefit modern society. In these applications, there is persistent pressure for systems with smaller size, lighter weight, and lower cost. For portable and wireless systems, such as the smart phones, tablets, wearable/implantable electronics, there are emerging technological needs for magnetic structures with size dimension in the range of microns to tens of microns, i.e. magnetic thick films. These films must possess good material performance but also be integrable/compatible with the manufacturing processes used for fabrication of end devices and systems. Today, the dominant technology is wafer-level microfabrication on silicon substrates.

Unfortunately, the development of high-performance permanent magnet thick films has been limited [1]-[3] due to a number of material and technological challenges. First, the best performing (highest energy density) rare-earth hard magnetic materials are highly prone to oxidation, the importance of which is amplified at small length scales (high surface area to volume ratio). Second, the extrinsic material properties of hard magnets are typically very 
sensitive to crystallinity and microstructure. This requires careful control over the processing conditions and may necessitate magnetic fields, additional thermal steps, or other processing steps, thus adding cost and complexity. Third, in application, hard magnets are commonly used for their stray magnetic fields, and in most cases, the larger the magnetic field, the better the performance of the device or system. This necessitates relatively thick layers (microns, tens of microns, or even hundreds of microns) to produce high magnetic fields over large air gaps or regions of space.

The most obvious first candidates for thick-film hard magnets would be the rare-earth alloys such as $\mathrm{Nd}-\mathrm{Fe}-\mathrm{B}$ or $\mathrm{Sm}-\mathrm{Co}$ because of their typically high remanent magnetization and energy product [1]-[3]. As an example, Dempsey, et al. reported 40- $\mu$ m-thick sputtered $\mathrm{Nd}-\mathrm{Fe}-\mathrm{B}$ films with energy density up to $400 \mathrm{~kJ} / \mathrm{m}^{3}$ (matching that of bulk) using a Ta capping layer to mitigate oxidation [4]. However, with sputtering or other physical vapor deposition methods, there is no way to pattern these thick films into the well-controlled shapes necessary for end devices. Photoresist liftoff is not possible due to the necessary high deposition temperatures, and there is no simple directional/selective etchant for chemical etching. The rare-earth metals also cannot be electroplated from aqueous baths.

As an alternative to the rare-earth alloys, $\mathrm{L}_{0}$-ordered equiatomic alloys of $\mathrm{CoPt}$ and $\mathrm{FePt}$ have garnered attention as candidate permanent magnet materials for microsystem applications. The $\mathrm{L} 1_{0}$ phase is a 50:50 composition of $\mathrm{Co}$ (or $\mathrm{Fe}$ ) with $\mathrm{Pt}$, having an asymmetric face-centered tetragonal (fct) structure. The asymmetric lattice gives rise to an exceptionally strong magnetocrystalline anisotropy $\left(K_{\mathrm{u}}=\sim 5 \mathrm{MJ} / \mathrm{m}^{3}\right.$ for CoPt $)$ along the c-axis. CoPt offers excellent chemical/thermal stability, good magnetic properties $\left(\mathrm{H}_{\mathrm{ci}}>800 \mathrm{kA} / \mathrm{m}\right.$, squareness close to $1, \mathrm{~B}_{\mathrm{r}}>$ $0.8 \mathrm{~T}$, and $\mathrm{BH}_{\max }>100 \mathrm{~kJ} / \mathrm{m}^{3}$ ), and ability for synthesis via electroplating [5], [6], [7]. A hightemperature deposition temperature or post-deposition anneal (usually up to $700^{\circ} \mathrm{C}$ ) is typically required to induce a structural transformation from the as-deposited disordered A1 phase having a face centered cubic (fcc) lattice to the ordered fct-structured $\mathrm{L} 1_{0}$ phase with strong magnetic performance. While CoPt has found little utility as a bulk magnetic material due to the high cost of $\mathrm{Pt}$, for film-based magnets, the material cost is not a dominant or limiting factor.

The fabrication of CoPt magnetic thin films has been widely studied for magnetic recording media with thicknesses typically $\ll<1 \mu \mathrm{m}$ [6]-[15], and for microsystem applications with thicknesses $1-10 \mu \mathrm{m}$ [16]-[22]. These prior reports on thicker films have focused on the effects of alloy composition on the magnetic behavior [16]-[18], crystallographic structure analysis of films deposited on $\mathrm{Cu}$ substrates [19] and the deposition of CoPt into nanoporous templates [20][22]. However, there is no comprehensive report of the interdependent relationships between the process parameters for fabricating thick electroplated CoPt films, the resultant crystallographic structure, and the corresponding magnetic performance.

The most common deposition techniques for fabrication of CoPt films are physical vapor deposition (sputtering or evaporation) and electrochemical deposition. While vacuum-based physical deposition methods are seen as "cleaner" techniques, electroplating is generally considered more practical for deposition of multi-micron-thick films. More so, from a manufacturing standpoint, electroplating offers high deposition rates, low equipment cost, low material wastage, good shape fidelity, and relatively easy scalability to large substrates [23], [24]. However, because electroplating generally lacks the control and purity of vacuum-based methods, electroplated layers are prone to impurities (such as oxygen, sulfur, phosphorous, and boron) and/or multiple material phases. Electroplating also introduces many process variables, such as temperature, stirring, current density, and bath $\mathrm{pH}$ and composition. These variables can be a 
blessing or a curse, due to the complex relationships between the process conditions and material properties such as grain size, film composition, film thickness, and crystallographic orientation. All of these material and structural properties influence the resultant magnetic properties and are the subject of the study reported in this article.

In a previous report [25], we reported electroplated CoPt films up to $20 \mu \mathrm{m}$ thick and briefly studied the dependence of the magnetic properties on annealing temperatures from $400^{\circ} \mathrm{C}$ to $800^{\circ} \mathrm{C}$. In the work reported here, a more comprehensive and systematic study of the influence of various process conditions on the structure and magnetic properties of electroplated thick-film $\mathrm{CoPt}$ magnets is conducted in order to establish optimal process parameters and to explore fundamental process/structure/property relationships. Section 2 reports the experimental methods, including the material fabrication and characterization. Sections 3, 4, and 5 discuss the influence of current density, film thickness, and annealing parameters, respectively. Section 6 presents conclusions that summarize the studies.

\section{Experimental Methods}

This section presents the experimental procedures including the electroplating and postdeposition annealing processes for the fabrication of CoPt magnet samples used in this work. The techniques used for material characterization are also identified.

\subsection{Fabrication}

In our standard process, CoPt is electroplated at room-temperature into $3.5 \mathrm{~mm}$ x $3.5 \mathrm{~mm} \times 7 \mu \mathrm{m}$ thick photoresist (AZ9260) molds onto metal seed layers on (100)Si substrates. As described further below, the seed layers include various combinations of sputtered TiN ( $25 \mathrm{~nm})$ to inhibit metal silicide reactions, $\mathrm{Ti}(10 \mathrm{~nm})$ to improve adhesion, and $\mathrm{Cu}(100 \mathrm{~nm})$ to provide a highly conductive surface for electroplating. Constant-current (galvanostatic) electroplating is carried out at a standard current density of $100 \mathrm{~mA} / \mathrm{cm}^{2}$ (unless otherwise noted) at a $\mathrm{pH}$ of 7 in a citratebased bath containing $0.025 \mathrm{M}$ diammine-dinitro platinum (II) $\left[\mathrm{Pt}\left(\mathrm{NH}_{3}\right)_{2}\left(\mathrm{NO}_{2}\right)_{2}\right], 0.1 \mathrm{M}$ cobaltous sulfamate $\left[\mathrm{Co}\left(\mathrm{NH}_{2}\right)_{2}\left(\mathrm{SO}_{3}\right)_{2}\right]$ salts, and a $0.1 \mathrm{M}$ ammonium citrate $\left[\left(\mathrm{NH}_{4}\right)_{2} \mathrm{C}_{6} \mathrm{H}_{6} \mathrm{O}_{7}\right]$. The ammonium citrate serves as a complexing agent to bridge the gap in the reduction potentials of $\mathrm{Co}\left(-0.28 \mathrm{~V}\right.$ at $\left.25^{\circ} \mathrm{C}\right)$ and $\mathrm{Pt}\left(+1.13 \mathrm{~V}\right.$ at $\left.25^{\circ} \mathrm{C}\right)$.

To induce the disordered to ordered $\mathrm{L} 1_{0}$ phase transition, samples are annealed in a tube furnace at a temperature of $700^{\circ} \mathrm{C}$ (unless otherwise stated) using a ramp rate of $20^{\circ} \mathrm{C} / \mathrm{min}$ and a dwell time of $40 \mathrm{~min}$ in forming gas ambient $\left(4 \% \mathrm{H}_{2}+96 \% \mathrm{~N}_{2}\right)$. Figure 1 shows a cross section SEM image of an example $\mathrm{L1}_{0} \mathrm{CoPt}$ magnetic layer after post-deposition annealing. 


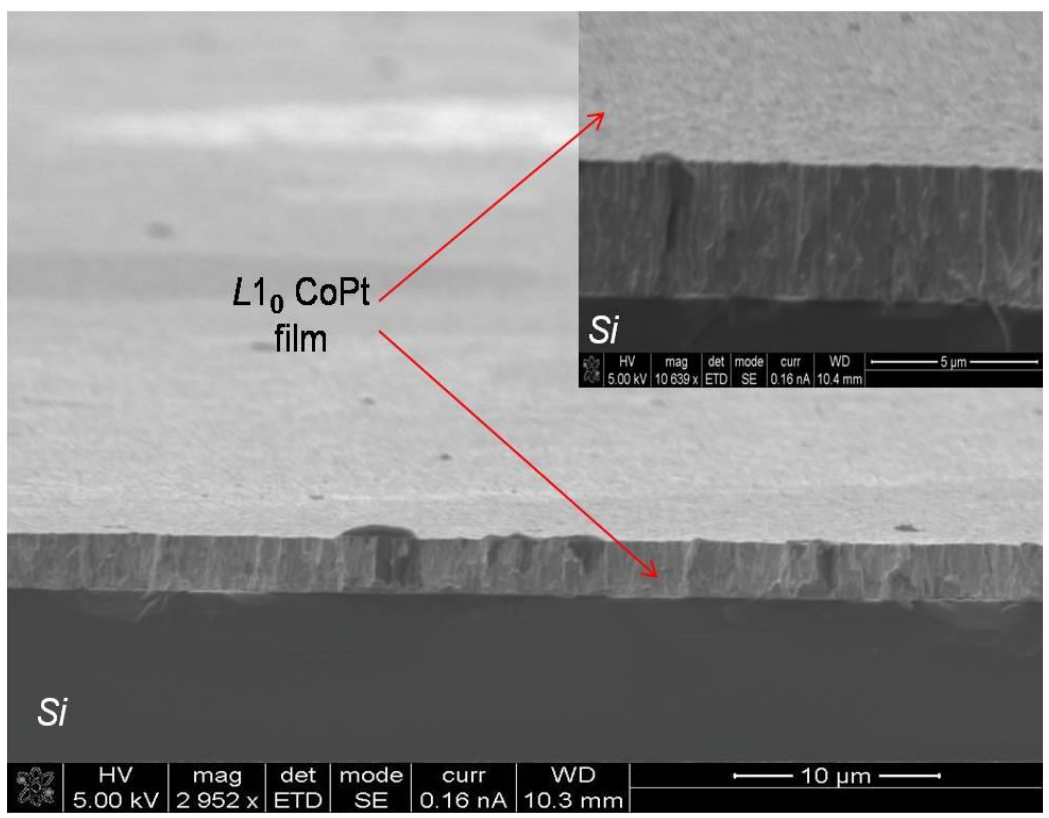

Figure 1: Example SEM image of electroplated and annealed CoPt thick films on (100)Si substrate with $100 \mathrm{~nm} \mathrm{Cu/10} \mathrm{nm} \mathrm{Ti} \mathrm{seed} \mathrm{layer/adhesion} \mathrm{layer.}$

\subsection{Material Characterization Techniques}

Measurements of film thickness are made using a stylus profilometer Dektak 150, while rms surface roughness measurements are made using a Bruker Contour GT-I optical profilometer with a surface topography resolution of $<1 \mathrm{~nm}$. A FEI Nova NanoSEM 430 scanning electron microscope (SEM) equipped with an EDAX energy dispersive $\mathrm{x}$-ray spectroscopy (EDS) detector is used for imaging as well as elemental composition analysis of the magnetic films. Except where noted, all films reported here were measured to have an equiatomic Co:Pt ratio to within 5\%. Structural and crystallographic information are obtained from x-ray diffraction (XRD) patterns measured using a Panalytical X'Pert powder diffractometer with a $\mathrm{Cu} \mathrm{K \alpha}$ radiation $(\lambda=1.54 \AA)$. Diffraction angles from $68^{\circ}$ to $70^{\circ}$ are typically skipped to avoid strong diffraction intensities associated with the (400) peak from the Si substrate. It should be noted that the (220) $\mathrm{L} 1_{0} \mathrm{CoPt}$ peak at $\sim 69^{\circ}$ falls within this gap. Magnetic measurements of the in-plane and out-ofplane hysteresis loops are carried out using a vibrating sample magnetometer (VSM), ADE Technologies Model EV9, with maximum applied fields up to $2.5 \mathrm{~T}$. No demagnetization correction is applied to the magnetic data reported herein.

\subsection{XRD Analysis Methods}

$\mathrm{XRD}$ is used as a primary tool for analyzing the crystallographic structure and phase transformation of the films. PDF cards 03-065-8968 and 03-065-8969 are used for A1 and $\mathrm{L} 1_{0}$ CoPt phases, respectively. Using Bragg's equation,

$$
\sin ^{2} \theta=\frac{\lambda^{2}}{4 a^{2}} h^{2}+k^{2}+\frac{\lambda^{2}}{4 c^{2}} l^{2}
$$

the lattice parameters $a$ and $c$ can be estimated for the $\mathrm{L}_{0}$ phase. The $a$ parameter is obtained from the (110) peak observed in the fct $\mathrm{L}_{0}$ structure but not in the fcc A1 phase. The $c$ parameter is determined using any of the $(00 l)$ planes, i.e. either the superlattice peaks $(001)$, (003), or the fundamental peak (002). Here, the (001) and (002) peaks are used.

In order to quantify the degree of $\mathrm{L} 1_{0}$ ordering in the film, the methods described in [29] are used to calculate the "order parameter" $S$, where for equiatomic compositions, $S$ ranges from 0 
(completely disordered $\mathrm{A} 1$ phase) to 1 (perfectly ordered $\mathrm{L} 1_{0}$ phase). For analysis, two peaks are considered. First, a fundamental peak - a diffraction peak that can occur as a direct result of the formation of the fct structure (in other words, a split peak), e.g. the (002) peak. The second is a superlattice peak - a diffraction peak from an identical plane to the plane of the fundamental peak, i.e. any of the (001) peaks for the case of a (002) fundamental reflection. The ratio of the measured intensities of these two peaks $I_{M}$ is then compared with the calculated ratio of the intensities of the two peaks for a fully-ordered case $I_{C}$, i.e. where $S=1$. The order parameter is then calculated as

$$
\begin{gathered}
S=\sqrt{\left(\frac{I_{M}}{I_{C}}\right)} \\
I_{M}=\left(\frac{I_{(001)}}{I_{(002)}}\right)_{\text {measured }} \\
I_{C}=\left(\frac{I_{(001)}}{I_{(002)}}\right)_{\text {calculated }(S=1)}=\frac{\left[|F|^{2} \times p \times L \times e^{-2 M}\right]_{(001)}}{\left[|F|^{2} \times p \times L \times e^{-2 M}\right]_{(002)}}
\end{gathered}
$$

where $F$ is the structural factor, and for equiatomic CoPt, $F_{001}=2 S\left(f_{C o}-f_{P t}\right)$ and $F_{002}=$ $2\left(f_{C o}+f_{P t}\right)$ where $f$ is an atomic form factor; $p$ is the multiplicity factor associated with the symmetry of the crystal structure where $p=2$ for $(00 l)$ planes of a tetragonal lattice; $L$ is the Lorentz-polarization factor that accounts for geometric effects in the diffraction measurements and is calculated as 38.84; and $M$, dependent on Bragg's angle, is a Debye-Waller thermal factor and is calculated as 0.0193 [30].

Whereas the order parameter indicates the degree of ordering in the annealed CoPt material, the $\mathrm{L} 1_{0}$ volume fraction indicates what fraction of the CoPt has been transformed from the A1 phase into the $\mathrm{L} 1_{0}$ phase. This is an important parameter of the CoPt film, since the volume ratio of the $\mathrm{L} 1_{0}$ phase in the annealed CoPt has been shown to strongly influence the resultant magnetic properties [6], [14], [19]. The $\mathrm{L} 1_{0}$ volume fraction is estimated using the measured peaks from XRD patterns as

$$
V_{F}=\frac{I_{B} \cdot R I R_{A}}{I_{B} \cdot R I R_{A}+I_{A} \cdot R I R_{B}}
$$

where $R I R_{A}$ is the reference intensity ratio of the $\mathrm{A} 1$ phase, $R I R_{B}$ is the reference intensity ratio for the $\mathrm{L} 1_{0}$ phase, and $I_{A}$ and $I_{B}$ are the integrated intensities of peaks with A1 phase and $\mathrm{L} 1_{0}$ phase respectively.

The crystallite grain size of a phase is estimated using the Scherrer's equation,

$$
d=\frac{K \lambda}{\beta \cos \theta}
$$

where $d$ is the grain size to be estimated, $K$ is a constant referred to as the shape factor (usually taken as 0.9), $\beta$ is the full width at half maximum (FWHM) of the peak, $\lambda$ is the wavelength of radiation, and $\theta$ is the Bragg's angle of the peak. This equation is applied to a single diffraction peak, and then the average result from several peaks is taken to be the average grain size.

\section{Influence of current density on electroplated CoPt thick films}

One critical parameter of interest in the electroplating process is the electroplating current 
density. Higher current densities are generally desirable for faster plating rates, but the material properties of galvanostatically plated alloys can be very sensitive to current density [23], [24]. In this section, the influence of electroplating current density on both the material properties and magnetic behavior of $\sim 3 \mu \mathrm{m}$-thick equiatomic CoPt films is presented.

To study the influence of current density, samples are prepared at five different current densities - ranging from $25 \mathrm{~mA} / \mathrm{cm}^{2}$ to $200 \mathrm{~mA} / \mathrm{cm}^{2}$ - on Ti/Cu seed layers. Two samples are prepared for each current density; one is annealed at $700^{\circ} \mathrm{C}$ for $40 \mathrm{~min}$., while the other companion sample is reserved in the as-deposited state. In order to maintain the same total charge transfer $\left(180 \mathrm{C} / \mathrm{cm}^{2}\right)$ for all samples, the time of deposition is adjusted as the plating current density is varied. Table 1 presents the deposition time and the corresponding film thickness for each current density.

Table 1: Samples used in studying the influence of current density on electroplated CoPt magnets.

\begin{tabular}{|c|c|c|c|c|}
\hline Sample & $\begin{array}{c}\text { Current density } \\
\left(\mathbf{m A} / \mathbf{c m}^{2}\right)\end{array}$ & $\begin{array}{c}\text { Plating time } \\
(\mathbf{h r s})\end{array}$ & $\begin{array}{c}\text { Measured thickness } \\
(\boldsymbol{\mu m})\end{array}$ & $\begin{array}{c}\text { Calculated rate } \\
(\boldsymbol{\mu m} / \mathbf{h r})\end{array}$ \\
\hline $\mathrm{A}$ & 25 & 2.0 & 3.5 & 1.75 \\
\hline $\mathrm{B}$ & 50 & 1.0 & 3.2 & 3.2 \\
\hline $\mathrm{C}$ & 100 & 0.5 & 3.1 & 6.2 \\
\hline $\mathrm{D}$ & 150 & 0.33 & 3.1 & 9.3 \\
\hline $\mathrm{E}$ & 200 & 0.25 & 2.7 & 10.8 \\
\hline
\end{tabular}

Table 1 shows a range of film thickness from $3.5 \mu \mathrm{m}$ at $25 \mathrm{~mA} / \mathrm{cm}^{2}$ to $2.7 \mu \mathrm{m}$ at $200 \mathrm{~mA} / \mathrm{cm}^{2}$. Based on these measurements, Figure 2 plots the plating rates, which range from 1.75 to 10.8 $\mu \mathrm{m} / \mathrm{hr}$. The plating rate shows a fairly linear trend with current density, with deviation at 200 $\mathrm{mA} / \mathrm{cm}^{2}$.

Also shown in Figure 2 is the rms surface roughness (post annealing) of the CoPt film vs. current density. Films deposited at $50-150 \mathrm{~mA} / \mathrm{cm}^{2}$ show the lowest surface roughness (minimum of 20 $\mathrm{nm}$ at $100 \mathrm{~mA} / \mathrm{cm}^{2}$ ), whereas a huge surface roughness of $1.8 \mu \mathrm{m}$ is observed at $200 \mathrm{~mA} / \mathrm{cm}^{2}$. So while increasing current density may yield faster plating rates, the roughness of the film surface will ultimately become an issue.

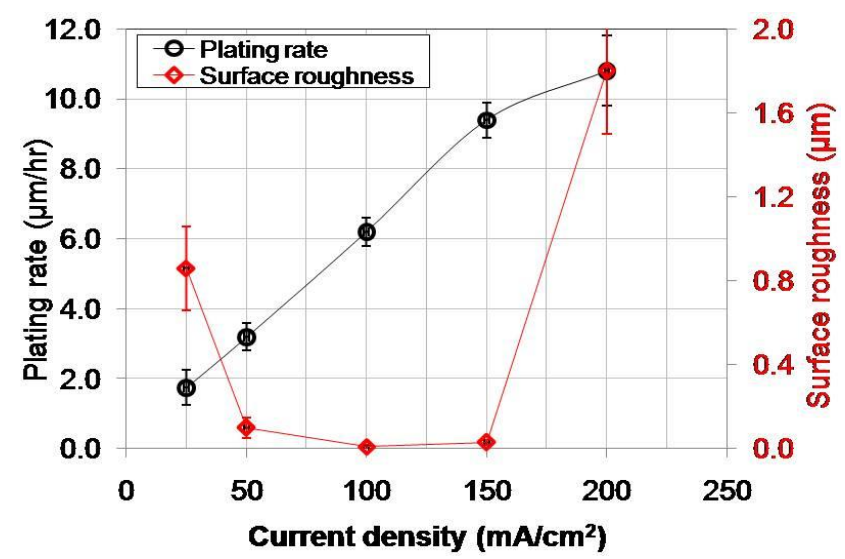

Figure 2: Plating rate and rms surface roughness of CoPt magnetic films deposited at various current densities. 
Shown in Figure 3 are wide-view SEM images of the CoPt film surfaces before annealing along with surface topography measurements of the films after annealing. Changes in the surface morphology of the magnets are observed with variation in current density. At low $\left(25 \mathrm{~mA} / \mathrm{cm}^{2}\right)$ and high $\left(200 \mathrm{~mA} / \mathrm{cm}^{2}\right)$ current densities, large surface cracks are present in the as-deposited film. After annealing, these cracks propagate through the film, which leads to loss of material in the annealed sample, as shown in the case of sample E.
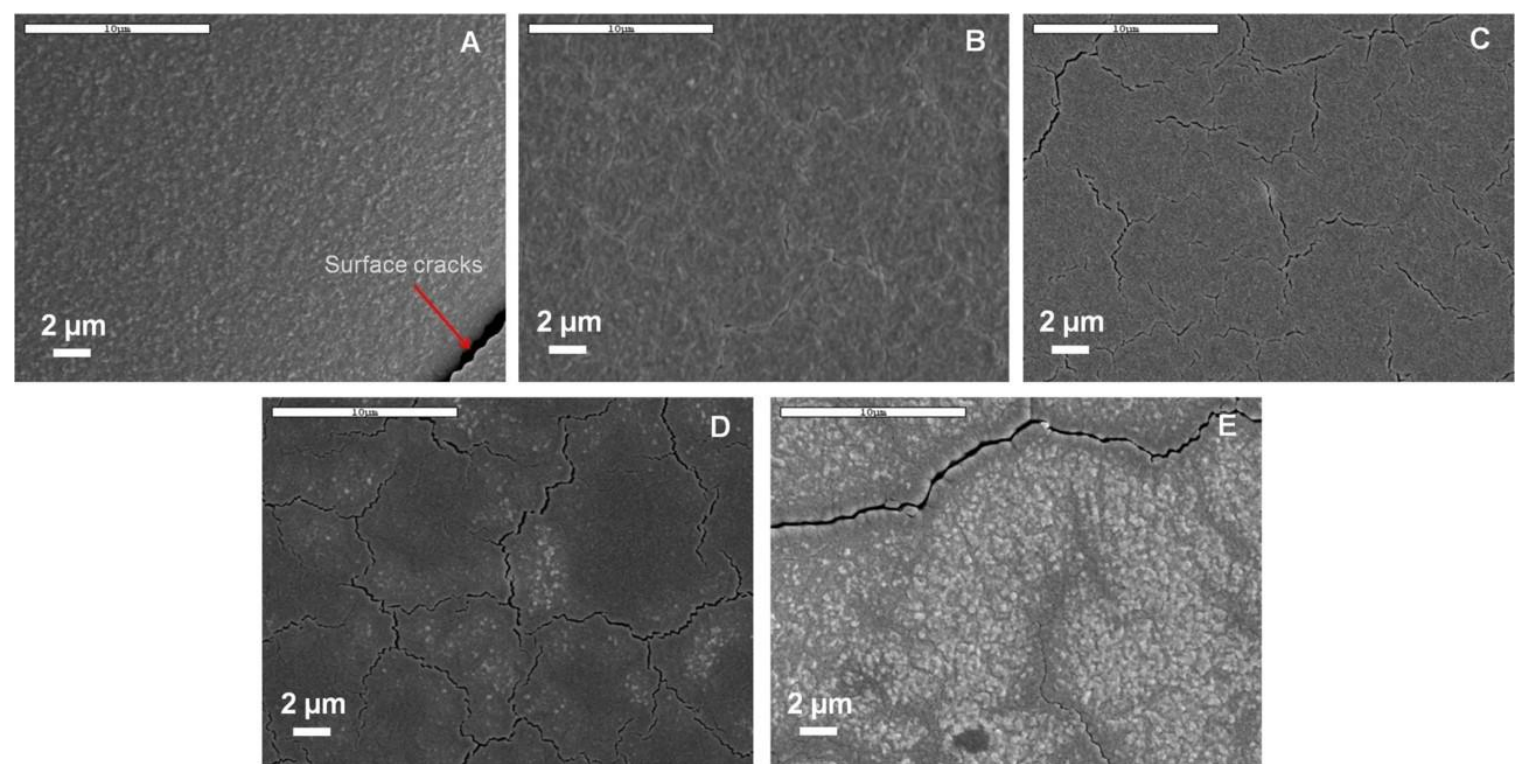

Figure 3: CoPt films deposited at (A) 25, (B) 50, (C) 100, (D) 150 and (E) $200 \mathrm{~mA} / \mathrm{cm}^{2}$ current densities: (top) SEM images showing surface morphologies of as-deposited films and (bottom) surface topography of annealed films.

EDS measurements indicated Co and $\mathrm{Pt}$, with a small trace $(<2 \%)$ of $\mathrm{B}$, which was subsequently eliminated from the compositional analysis. The atomic composition of the deposited films remains at $\sim 50: 50$ for all five tested current densities. This is attributed to the ammonium citrate complexing agent in the plating bath, which facilitates the co-deposition of $\operatorname{Co}\left(E_{0}=-0.28 \mathrm{~V}\right)$ and $\mathrm{Pt}\left(E_{0}=\sim 1.2 \mathrm{~V}\right)$ at similar reduction potentials by forming complexes with the metal ions [26][28]. Hence, whereas increasing the current density increases the rate of metallic ion reduction, the chemical composition of the alloy remains fairly constant since the metals are being reduced at similar potentials. This observation is consistent with results reported in [11].

Figure 4 shows XRD patterns, indicating a mixture of fct $\mathrm{L} 1_{0} \mathrm{CoPt}$ and fcc $\mathrm{A} 1 \mathrm{CoPt}$, along with diffraction peaks from the seed layer and substrate (described in more detail in Section 4). As indicated in the figure, distinct $\mathrm{L} 1_{0}$ peaks of (110), (201), (202), and (221) are observed at approximately $33^{\circ}, 54^{\circ}, 71^{\circ}$, and $75^{\circ}$ diffraction angles, respectively. The shared (111), (200), and (311) A1/L1 $1_{0}$ peaks are observed at $41.5^{\circ}, 48^{\circ}$, and $85^{\circ}$ diffraction angles, respectively. Table 2 summarizes the calculated lattice parameters for the $\mathrm{L} 1_{0} \mathrm{CoPt}$ magnets, which agree with values reported in [31] for equiatomic CoPt. Here, the smallest axial ratio (c/a) is obtained for sample $\mathrm{C}$ deposited at $100 \mathrm{~mA} / \mathrm{cm}^{2}$ currents. 


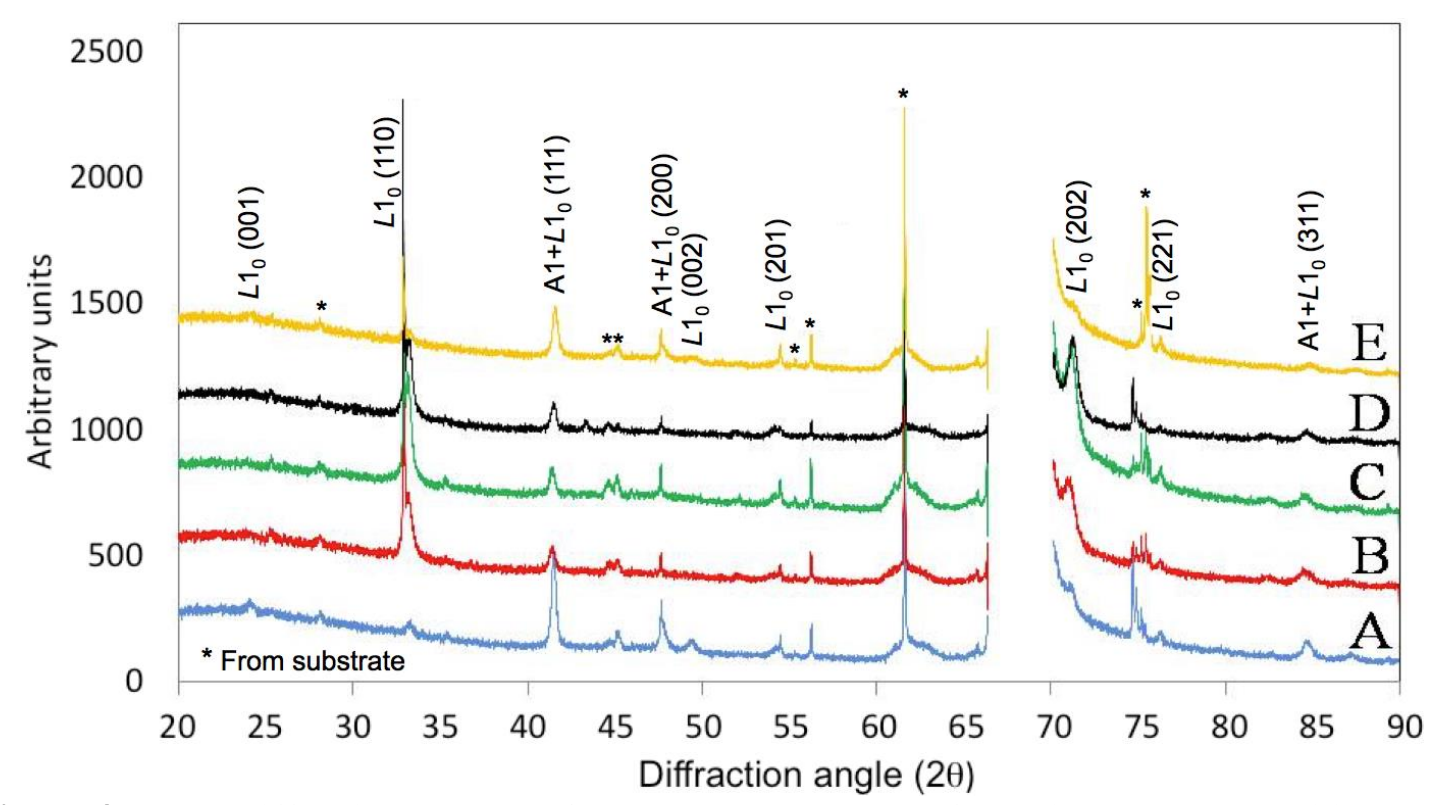

Figure 4: X-ray diffraction patterns of annealed CoPt samples for various current densities.

Table 2: Estimated lattice parameters $a$ and $c$, and axial ratio $(c / a)$ for samples A-E after annealing.

\begin{tabular}{|c|c|c|c|}
\hline Sample & $\begin{array}{c}\text { a (nm), calculated using } \\
(\mathbf{1 1 0}) \text { peak }\end{array}$ & $\begin{array}{c}\mathbf{c}(\mathbf{n m}) \text {, calculated using } \\
(\mathbf{0 0 1}) \text { and (002) peaks }\end{array}$ & c/a \\
\hline A & 0.381 & 0.376 & 0.986 \\
\hline B & 0.385 & 0.376 & 0.978 \\
\hline C & 0.385 & 0.375 & 0.976 \\
\hline D & 0.385 & 0.376 & 0.978 \\
\hline E & 0.384 & 0.376 & 0.980 \\
\hline
\end{tabular}

Figure 5 shows the order parameter for annealed samples deposited at different current densities. The order parameters for samples $\mathrm{C}$ and $\mathrm{D}$ are about $80 \%$, but only $\sim 65 \%$ in samples $\mathrm{A}$ and $\mathrm{E}$. Figure 5 also plots the grain size (post annealing) of the $\mathrm{L} 1_{0} \mathrm{CoPt}$ phase, estimated from the (110) and (002) peaks using the Scherrer equation. There is no strong correlation of the grain size with current density. The $\mathrm{L} 1_{0}$ grain size ranges from $19 \mathrm{~nm}$ to $26 \mathrm{~nm}$ for all five samples. Figure 6 shows the estimated volume fraction for samples plated at different current densities. Here, there is a strong dependency with current density. The volume fraction of the $\mathrm{L} 1_{0}$ phase in the annealed CoPt samples varies from a minimum of $54 \%$ (at a current density of $200 \mathrm{~mA} / \mathrm{cm}^{2}$ ) to a maximum $88 \%$ (at $100 \mathrm{~mA} / \mathrm{cm}^{2}$ ). 


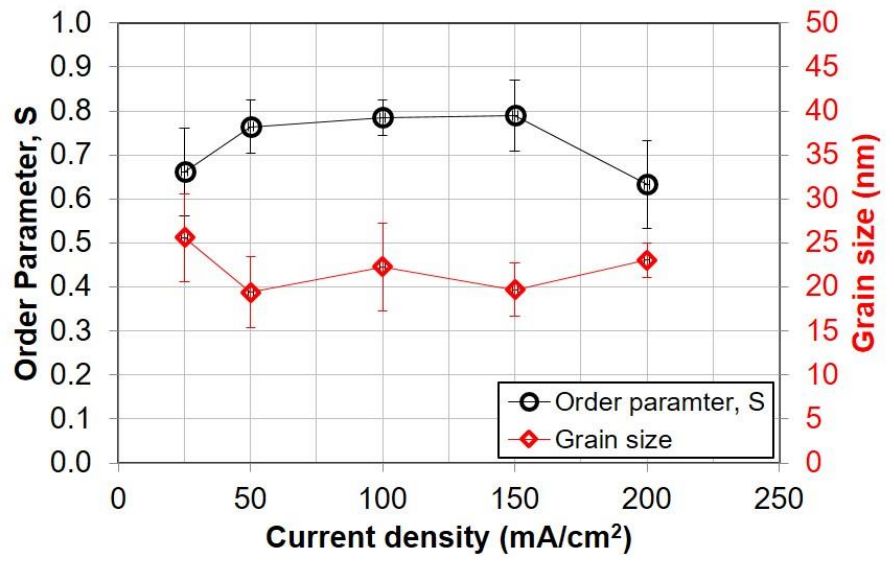

Figure 5: Order parameter and grain size of $\mathrm{L}_{0}$ phase for annealed CoPt samples deposited at various current densities.

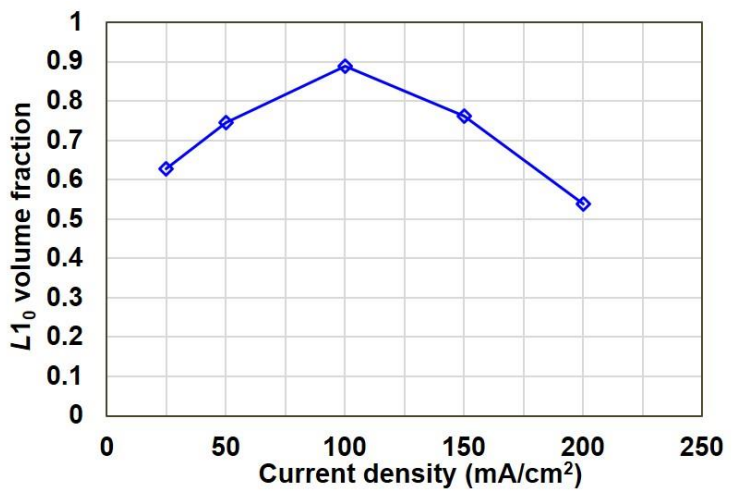

Figure 6: $\mathrm{L} 1_{0}$ volume fractions of annealed CoPt samples plated at different current densities.

Figure 7 shows in-plane and out-of-plane magnetic hysteresis curves measured for the postannealed films $\left(700^{\circ} \mathrm{C}, 40 \mathrm{~min}\right.$.). From these curves, Figure 8 summarizes the coercivity and squareness values, plotted versus current density. Figure 9 shows these magnetic properties plotted versus the $\mathrm{L} 1_{0}$ volume fraction.

The magnetic performance of the CoPt is fairly similar for samples deposited at $50-150 \mathrm{~mA} / \mathrm{cm}^{2}$ (samples B, C, and D). Sample C exhibits the largest coercivity, $900 \mathrm{kA} / \mathrm{m}$, and squareness, 0.95, of the samples tested. In contrast, samples $\mathrm{A}$ and $\mathrm{E}$ show lower coercivity and pronounced kinks in the $2^{\text {nd }}$ and $4^{\text {th }}$ quadrants, for both in-plane and out-of-plane directions. These kinks are attributed to the possible superposition of two magnetic phases in the annealed CoPt film (i.e., a low-coercivity A1 phase and/or some excess $\mathrm{Co}$, and a high-coercivity $\mathrm{L} 1_{0}$ magnetic phase). Samples A and E yield curves with pronounced kinks, whereas samples B, C, and D have much smaller kinks, which correlates with the $\mathrm{L} 1_{0}$ volume fraction. 

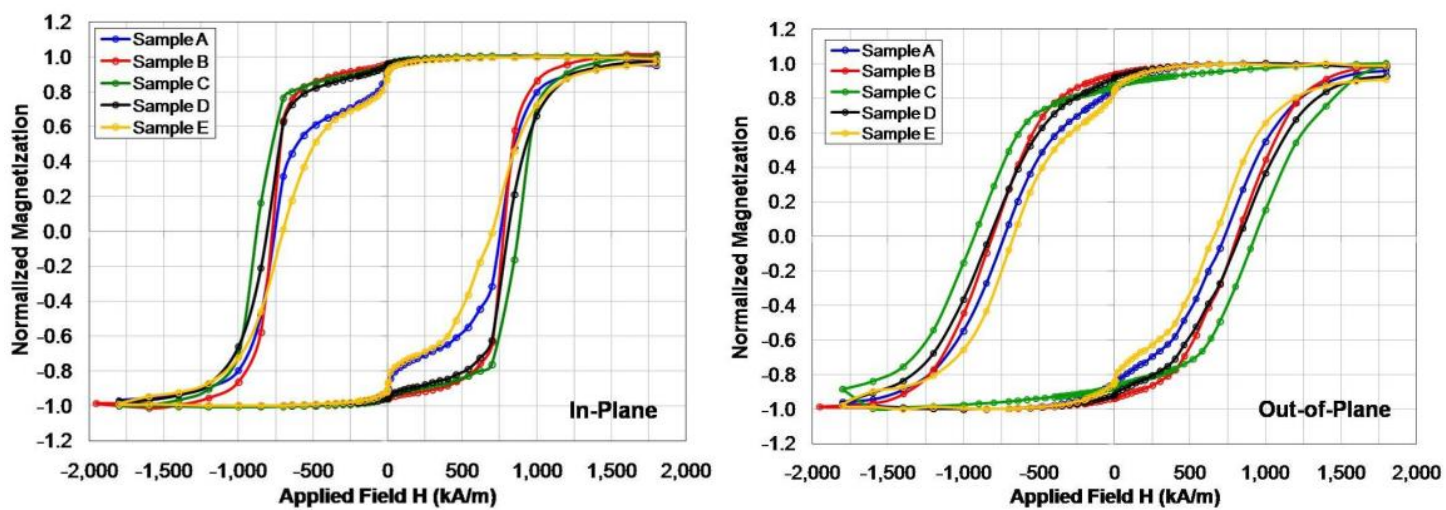

Figure 7: Magnetic properties (normalized M-H loops) of annealed CoPt samples deposited at different current densities: (left) in-plane, (right) out-of-plane.

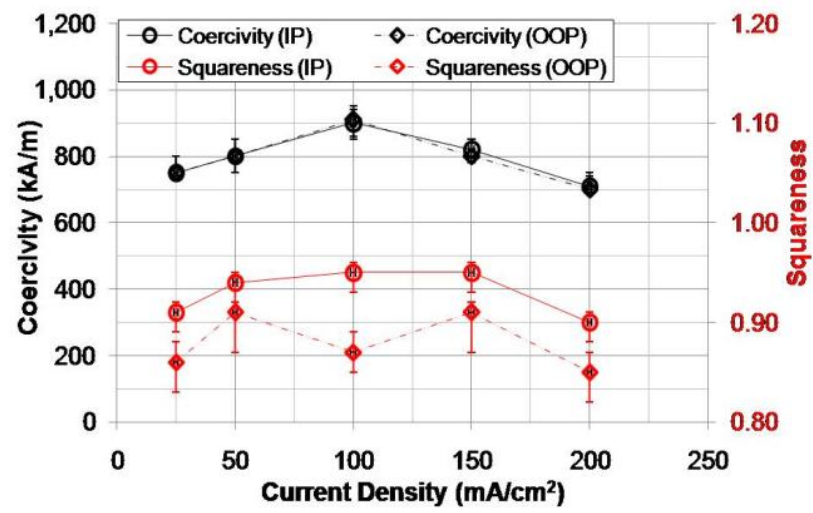

Figure 8: In-plane and out-of-plane intrinsic coercivity and squareness for CoPt samples deposited at various current densities.

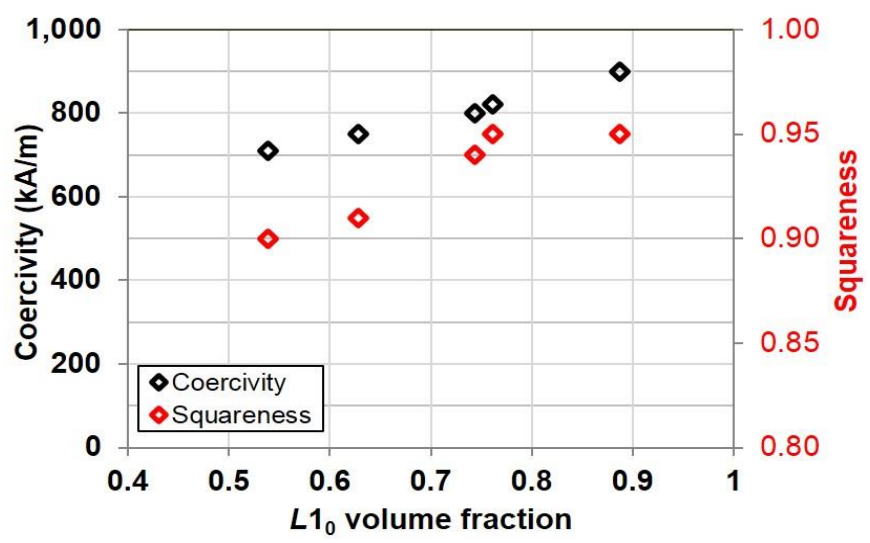

Figure 9: In-plane coercivity and squareness versus $\mathrm{L}_{0}$ volume fraction for annealed $\mathrm{CoPt}$ samples deposited at various current densities.

The difference in the shapes of the in-plane and out-of-plane magnetization curves is partially attributed to the shape anisotropy (demagnetization effect) of the magnetic films, which explains why there is a reduction in the squareness and more pronounced kinks for the out-of-plane measurements, but the coercivity remains the same for the in-plane and out-of-plane directions.

\section{Influence of film thickness on electroplated CoPt thick films}


In this section, the influence of film thicknesses from $0.5 \mu \mathrm{m}$ to $5 \mu \mathrm{m}$ on the magnetic properties of the CoPt layers. The use of a TiN diffusion barrier is also investigated to mitigate interfacial metal-silicide reactions. Type A samples use only a $10 \mathrm{~nm}$ Ti adhesion layer and a $100 \mathrm{~nm} \mathrm{Cu}$ conductive layer. Type B samples use a $25 \mathrm{~nm}$ TiN diffusion barrier, followed by $10 \mathrm{~nm}$ Ti and $100 \mathrm{~nm} \mathrm{Cu}$. All samples are plated at $100 \mathrm{~mA} / \mathrm{cm}^{2}$ currents and subsequently annealed at $700^{\circ} \mathrm{C}$ for $40 \mathrm{~min}$. For these experiments, the film thickness is controlled by the time of deposition, as summarized in Table 3.

Table 3: Deposition times and corresponding film thicknesses of CoPt layers.

\begin{tabular}{|c|c|c|c|}
\hline Sample & Layers & Deposition time (min) & Film thickness $(\boldsymbol{\mu m})$ \\
\hline $\mathrm{A} 1$ & $\mathrm{Si} / \mathrm{Ti} / \mathrm{Cu}$ & 5 & 0.4 \\
\hline $\mathrm{A} 2$ & $\mathrm{Si} / \mathrm{Ti} / \mathrm{Cu}$ & 15 & 1.3 \\
\hline $\mathrm{A} 3$ & $\mathrm{Si} / \mathrm{Ti} / \mathrm{Cu}$ & 30 & 2.6 \\
\hline $\mathrm{A} 4$ & $\mathrm{Si} / \mathrm{Ti} / \mathrm{Cu}$ & 45 & 3.5 \\
\hline $\mathrm{A} 5$ & $\mathrm{Si} / \mathrm{Ti} / \mathrm{Cu}$ & 60 & 5.2 \\
\hline $\mathrm{B} 1$ & $\mathrm{Si} / \mathrm{TiN} / \mathrm{Ti} / \mathrm{Cu}$ & 5 & 0.4 \\
\hline $\mathrm{B} 2$ & $\mathrm{Si} / \mathrm{TiN} / \mathrm{Ti} / \mathrm{Cu}$ & 15 & 1.3 \\
\hline $\mathrm{B} 3$ & $\mathrm{Si} / \mathrm{TiN} / \mathrm{Ti} / \mathrm{Cu}$ & 30 & 2.6 \\
\hline
\end{tabular}

Figure 10 shows cross-section SEM images of annealed CoPt magnets with various film thicknesses. As seen in this figure, the $0.4-\mu \mathrm{m}$-thick CoPt sample without TiN, exhibits a rough, pulverized appearance, suspected to be the result of a reaction with the Si substrate at temperatures $\geq 200^{\circ} \mathrm{C}$ [32], [33]. However, as the film thickness increases, this metal-silicide layer becomes progressively negligible and the microstructure of the CoPt film becomes clearly defined

Figure 10 clearly shows improvement of the $\mathrm{Si}$-metal interface with the addition of a TiN diffusion barrier layer. However, one new problem emerges as observed in the poorer adhesion of the $\mathrm{Ti} / \mathrm{Cu} / \mathrm{CoPt}$ layers to the TiN diffusion barrier. This poor adhesion leading to delamination of the metal layers from the Si substrate is more noticeable in large plated areas (e.g. $3.5 \mathrm{~mm}$ x 3.5 $\mathrm{mm})$, but no delamination was observed for smaller areas such as $5 \mu \mathrm{m} \times 50 \mu \mathrm{m}$. 

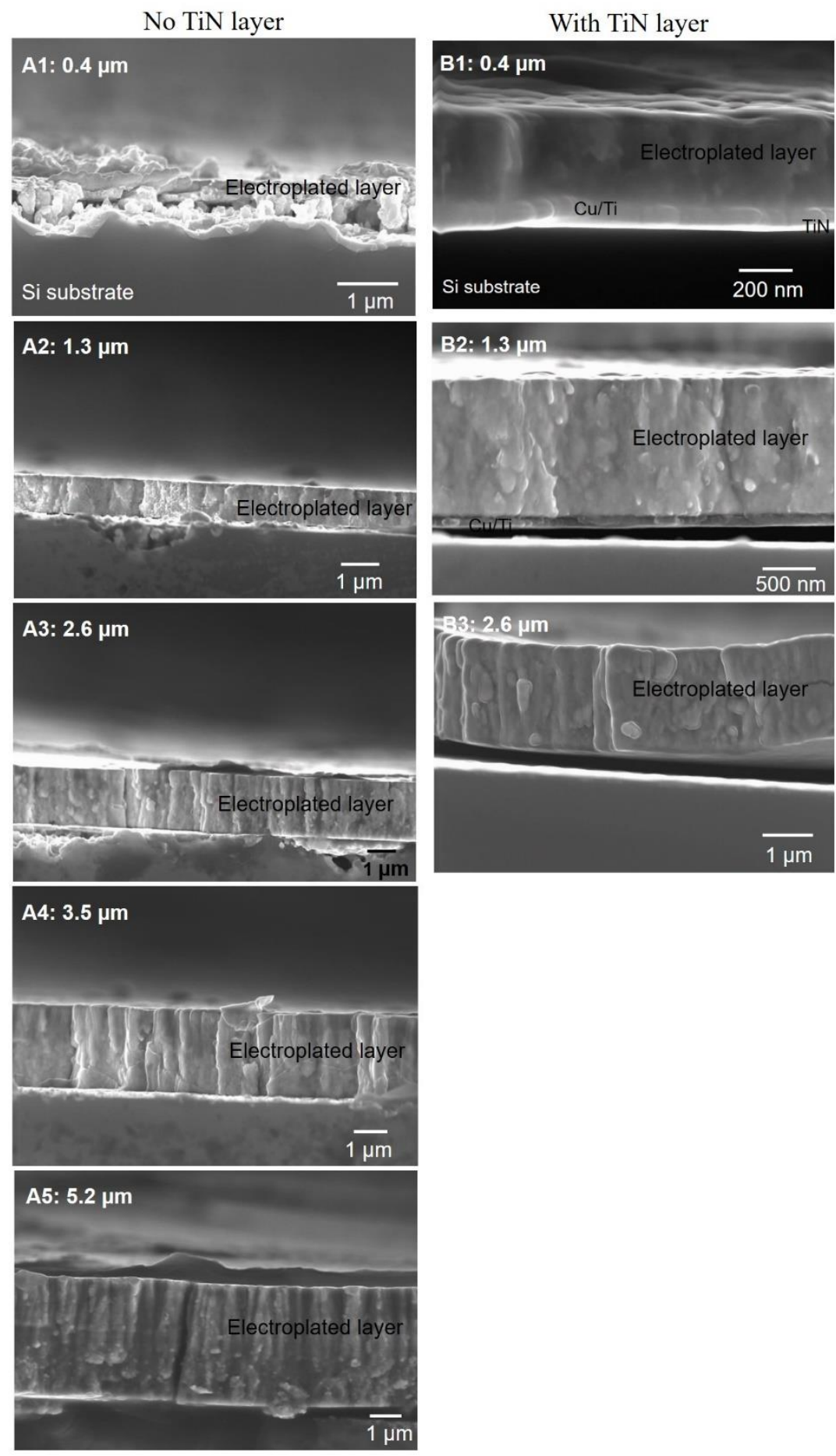

Figure 2: Cross-section SEM images of annealed CoPt films of various film thicknesses. (A1A5) shows without TiN layer. (B1-B3) shows with TiN diffusion barrier layer

The atomic composition of the films is confirmed from EDS measurements. All films show nearequiatomic composition (slightly Pt-rich) indicating that an increase in the CoPt film thickness does not influence changes in its atomic composition. Figure 11 shows XRD patterns of samples electroplated with and without TiN diffusion barrier confirming the presence of $\mathrm{Co}-$ and $\mathrm{Cu}-$ silicides, with strong peak intensities notable for the $0.4-\mu \mathrm{m}$-thick sample without TiN. The data 
also shows the elimination of the metal-silicides by adding a TiN diffusion barrier layer. Also observed here are the strong $\mathrm{Cu}$ peaks (at $43.5^{\circ}$ diffraction angle) for samples with $\mathrm{TiN}$ suggesting again that for these samples, the $\mathrm{Cu}-\mathrm{Si}$ reaction at the interface is prevented by the diffusion barrier layer.

Figures 12 and 13 show, respectively, the average grain size and the $\mathrm{L} 1_{0}$ phase volume fraction of Type A (without TiN) and Type B (with TiN) samples. For both sample types, the apparent grain size - measured using the (110) and (201) peaks - deceases with increasing film thickness, with no strong difference between the two. Conversely, the $\mathrm{L} 1_{0}$ volume fraction increases with film thickness, but there are substantial differences between the sample types. The Type A samples show $<40 \%$ volume fraction until the $3.5-\mu \mathrm{m}$-thick samples, whereas the Type B samples shows $\geq 70 \%$ volume fraction for the $1.3-\mu \mathrm{m}$-thick sample and above. The low volume fraction observed in the thinner Type A film (no TiN) is attributed to the formation of metal silicides, which can both consume Co or $\mathrm{Pt}$ and inhibit the kinetics of the $\mathrm{A} 1 \rightarrow \mathrm{L} 1_{0}$ transformation.

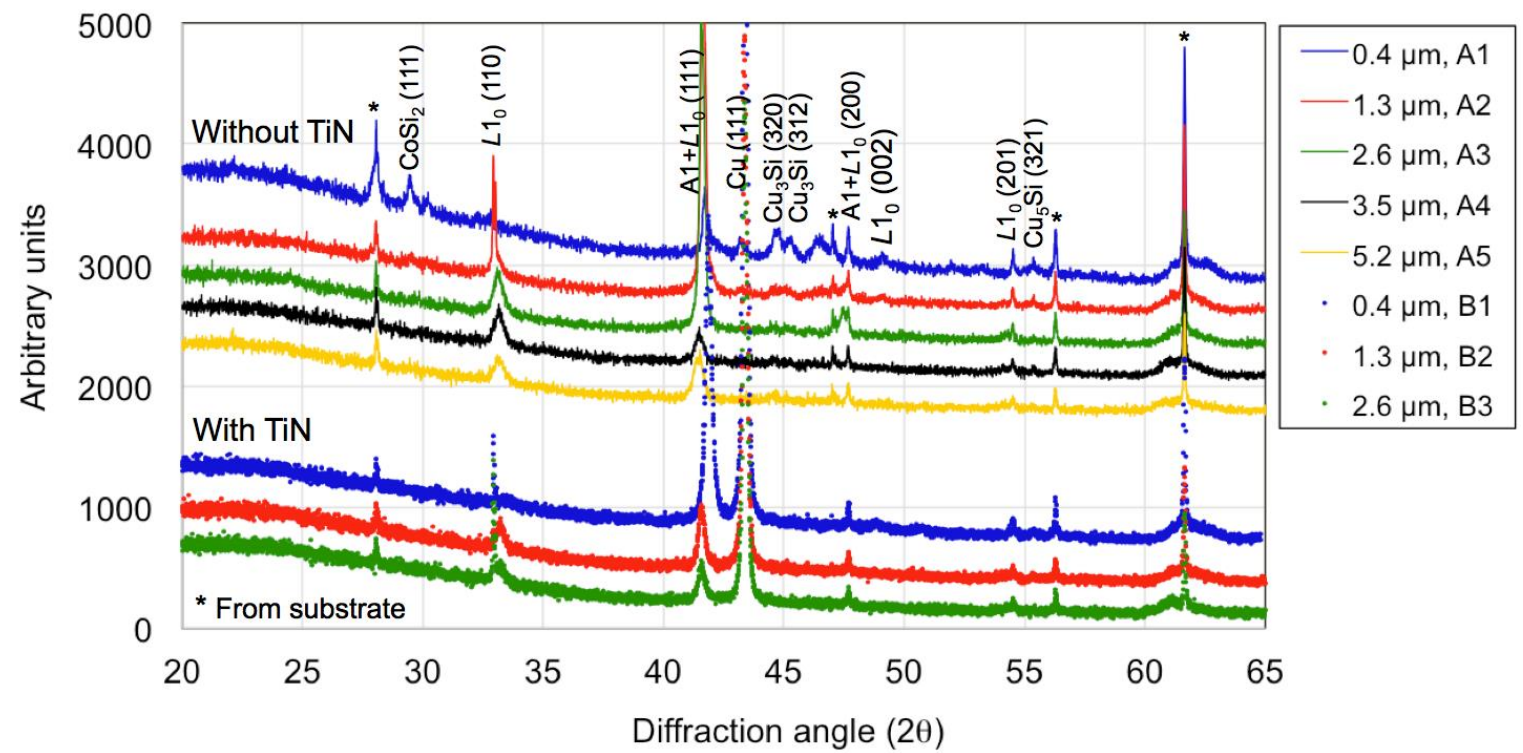

Figure 3: XRD patterns of annealed CoPt films of different thicknesses with (B samples) and without (A samples) TiN diffusion barrier.

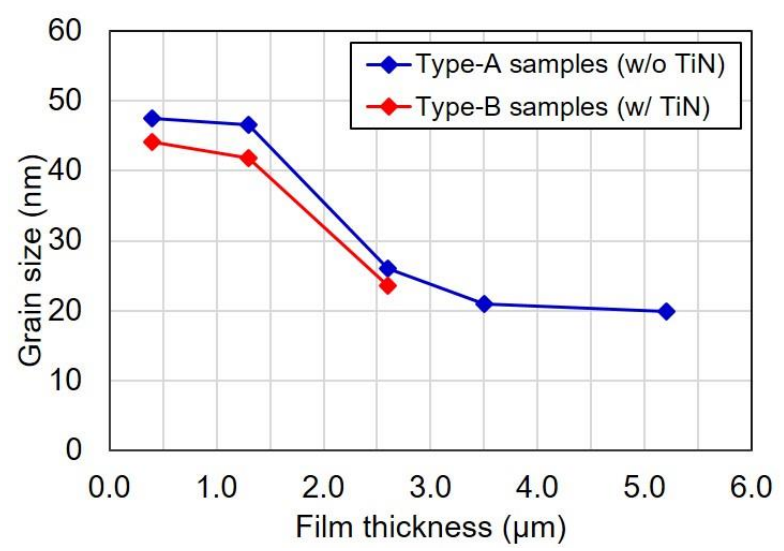

Figure 4: Grain size of $\mathrm{L}_{0}$ phase of annealed CoPt samples of various thicknesses. 


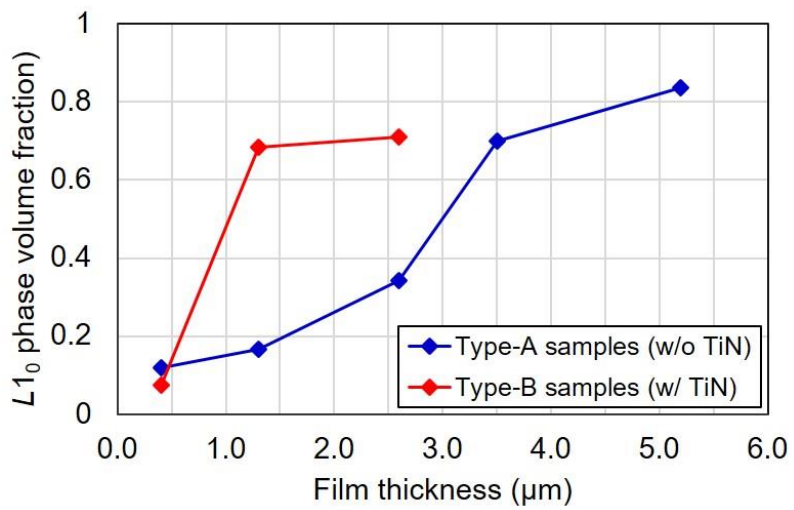

Figure 5: $\mathrm{L}_{0}$ phase volume fraction of annealed CoPt samples of various thicknesses.

Figure 14 presents the magnetic properties of the samples without TiN diffusion barrier layer, while Figure 15 shows the magnetic properties with the TiN layer. As shown, the samples without the diffusion barrier shows very poor hysteresis loops for the $0.4-\mu \mathrm{m}$-thick magnet, owing to the large volume fraction of non-magnetic silicides. Substantial improvements are observed for samples with the TiN barrier layer, which are attributed to the elimination of the non-magnetic silicides in the films and improvement in the $\mathrm{L}_{0}$ phase transformation. However, poor magnetic properties are still measured for films less than $1 \mu \mathrm{m}$, even with TiN diffusion barrier layer. This is suspected to be a result of intermixing between the non-magnetic $\mathrm{Cu}$ seed layer and the CoPt magnetic film during annealing.
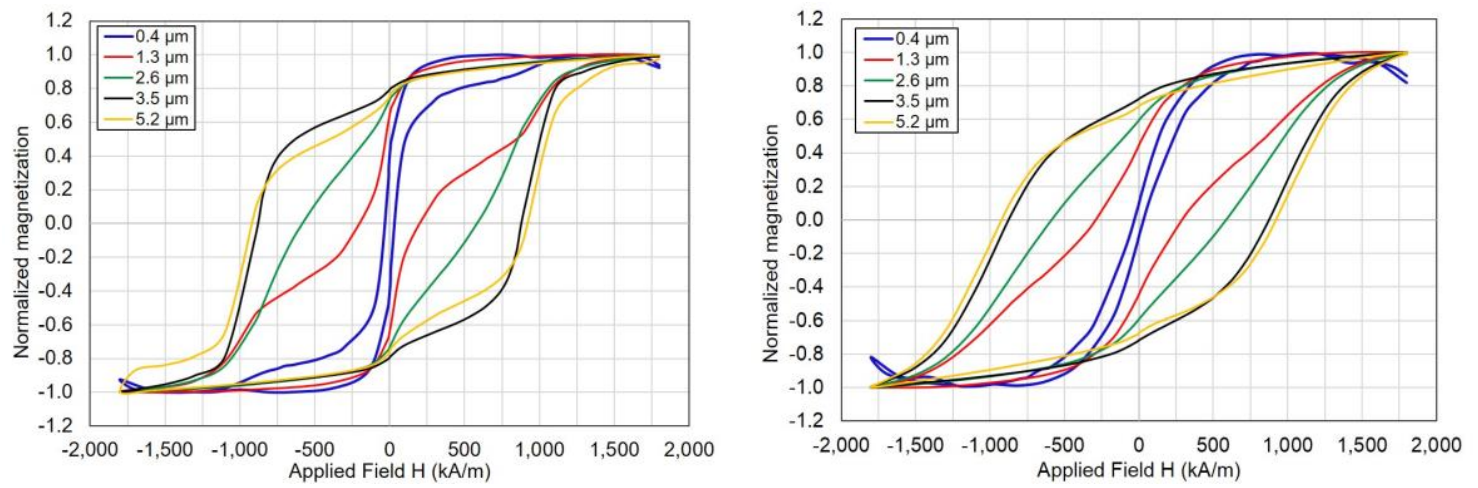

Figure 6: In-plane (left) and out-of-plane (right) magnetic hysteresis curves for annealed CoPt samples without TiN diffusion barrier layer. 

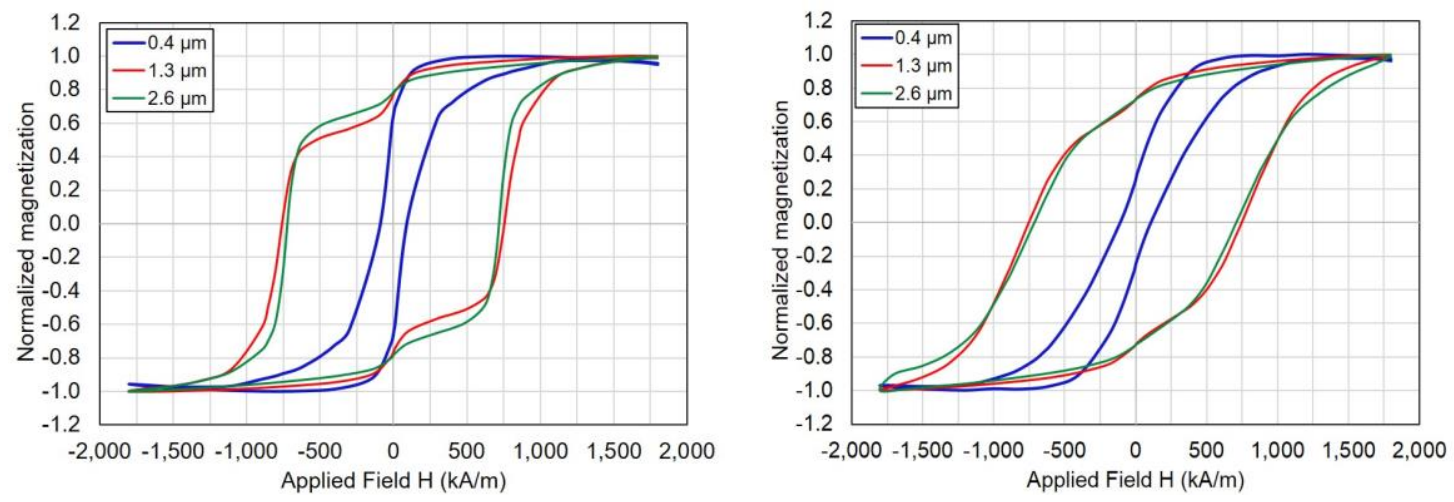

Figure 15: In-plane (left) and out-of-plane (right) magnetic hysteresis curves for annealed CoPt samples with TiN diffusion barrier layer.

The observation that the magnetic properties improve with thickness suggests the existence of a "good" magnetic layer on top of a "poor" layer, as illustrated in Figure 16. This may also explain the "kinks" observed in the magnetic hysteresis loops of many of the samples. Films at $3.5 \mu \mathrm{m}$ and above show properties consistent with those presented in earlier reports for 3-um to $20-\mu \mathrm{m}$ thick layers (Section 3 and [25]).

The coercivities of all eight Type A and Type B films are plotted against the $\mathrm{L} 1_{0}$ volume fraction for the same film thickness in Figure 17. This plot confirms that the coercivity of the CoPt film increases as the $\mathrm{L}_{0}$ volume fraction increases, a trend that is attributed to the strong magnetocrystalline anisotropy of the $\mathrm{L} 1_{0}$ phase.
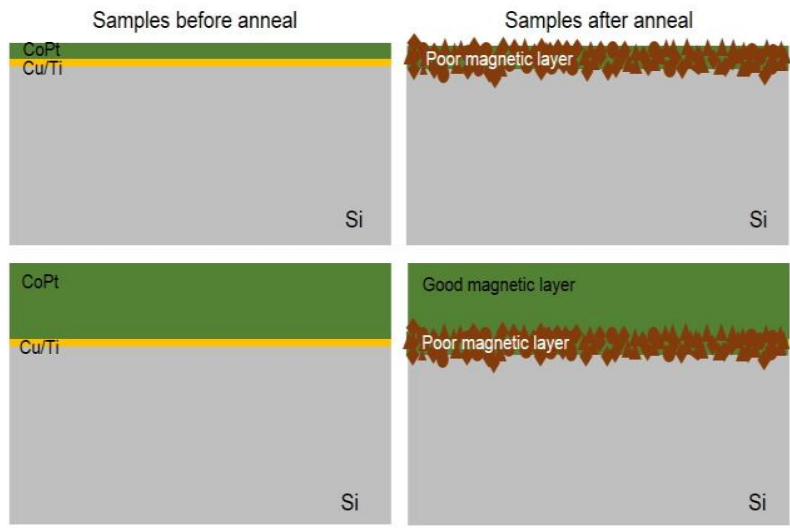

Figure 7: Schematic illustrating why magnetic properties improve with increase in CoPt film thickness for samples deposited on $\mathrm{Cu} / \mathrm{Ti}$. 


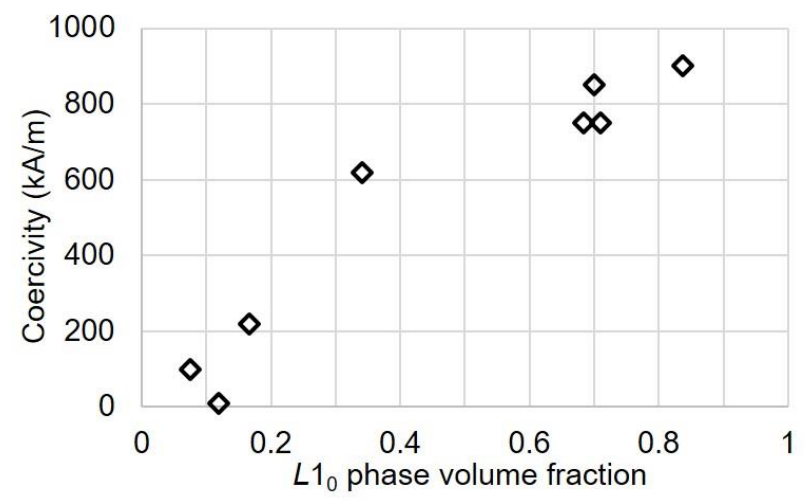

Figure 17: Coercivity vs. $\mathrm{L} 1_{0}$ volume fraction for annealed CoPt films with various thicknesses.

\section{Influence of anneal parameters on electroplated CoPt thick films}

Our previous work [25] reported anneal temperatures of $400^{\circ} \mathrm{C}$ up to $800^{\circ} \mathrm{C}$ in increments of $100^{\circ} \mathrm{C}$, with a fixed anneal time of $40 \mathrm{~min}$. To further explore the effects of annealing, finer temperature increments are explored $\left(625^{\circ} \mathrm{C}, 650^{\circ} \mathrm{C}, 675^{\circ} \mathrm{C}\right.$, and $\left.700^{\circ} \mathrm{C}\right)$ along with various annealing times ( $10 \mathrm{~min}, 20 \mathrm{~min}, 30 \mathrm{~min}, 1 \mathrm{hr}$, and $2 \mathrm{hr}$ ) at $675^{\circ} \mathrm{C}$. The CoPt samples here are plated for $60 \mathrm{~min}$ on $\mathrm{Ti} / \mathrm{Cu}$ seed layers using $100 \mathrm{~mA} / \mathrm{cm}^{2}$ currents (nominal film thickness of 6 $\mu \mathrm{m})$ and then annealed for $40 \mathrm{~min}$. at various temperatures or alternatively various times at $675^{\circ} \mathrm{C}$.

Figure 18 shows the diffraction patterns for samples annealed at different temperatures. The diffraction peaks from CoPt are labeled, with several other peaks (not labeled) from the $\mathrm{Si}$ substrate and seed layers. In the as-deposited state, the A1 CoPt phase exhibits $5 \mathrm{~nm}$ grain size, as measured from the (200) and (111) peaks. As the anneal temperature increases, the peaks indicative of the $\mathrm{L} 1_{0}$ phase-(110), (201), (112), (202)-become more pronounced. As shown in Figure 19, the grain size of the $\mathrm{L} 1_{0}$ phase - estimated using the (110) and (202) peaks - increases with temperature, up to $21 \mathrm{~nm}$ for the sample annealed at $700^{\circ} \mathrm{C}$.

The in-plane and out-of-plane magnetic properties of the samples are shown in Figure 20. The highest coercivity is recorded for the sample annealed at $700^{\circ} \mathrm{C}$, which correlates with the high $\mathrm{L} 1_{0}$ peak intensity observed in the XRD patterns. The data also shows a reduction in saturation magnetization with increase in anneal temperatures. Figure 21 plots the coercivity and energy product for these samples. Although the highest coercivity is recorded for samples annealed at $700^{\circ} \mathrm{C}$, the maximum energy product is obtained at $675^{\circ} \mathrm{C}$.

Further experiments are carried out to investigate the influence of anneal time on the magnetic properties of $\mathrm{L}_{0} \mathrm{CoPt}$ magnets. Figure 22 presents the out-of-plane and in-plane magnetization curves for samples annealed at $675^{\circ} \mathrm{C}$ for different times. It is seen here that the magnetic properties steadily improve for films annealed for $30 \mathrm{~min}$ and remain relatively constant with annealing even up to $2 \mathrm{hr}$. 


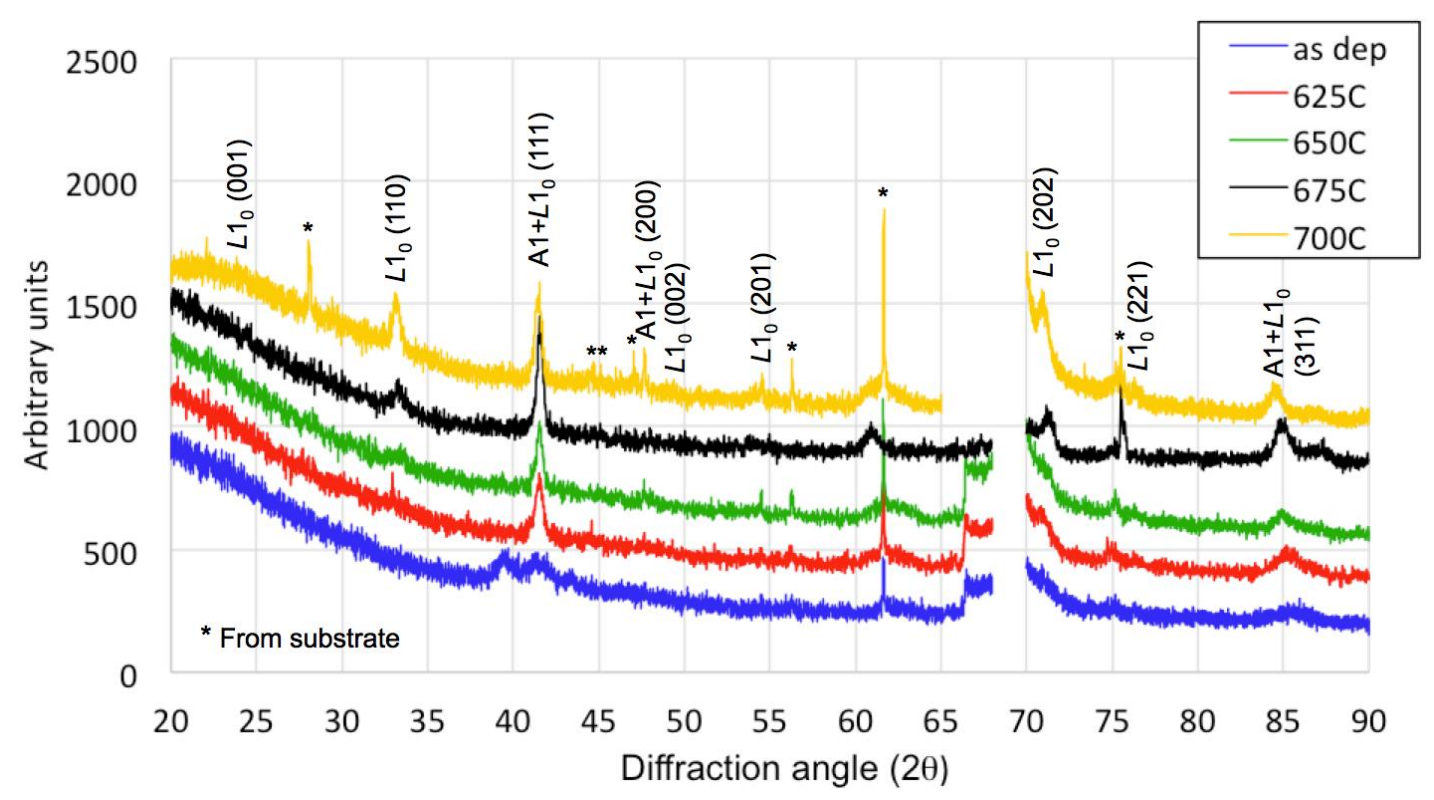

Figure 18: XRD patterns for samples annealed at temperatures between $625^{\circ} \mathrm{C}$ and $700^{\circ} \mathrm{C}$.

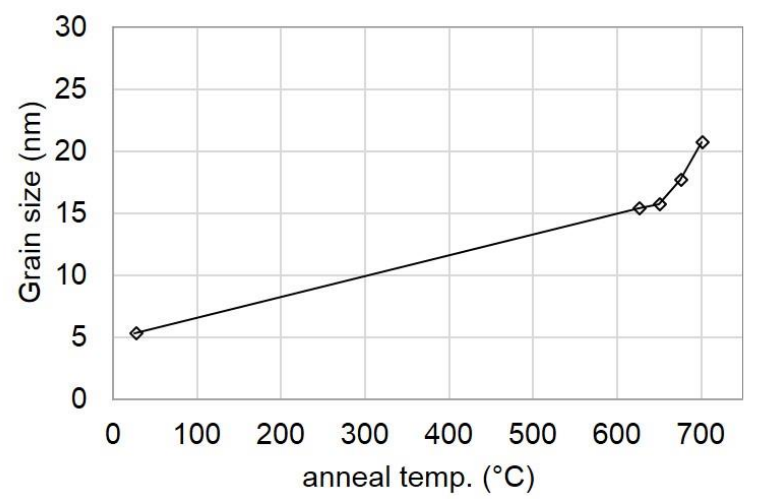

Figure 19: Grain size of $\mathrm{A} 1 \mathrm{CoPt}$ (as deposited) and $\mathrm{L} 1_{0} \mathrm{CoPt}$ phase (annealed samples) for different annealing temperatures.
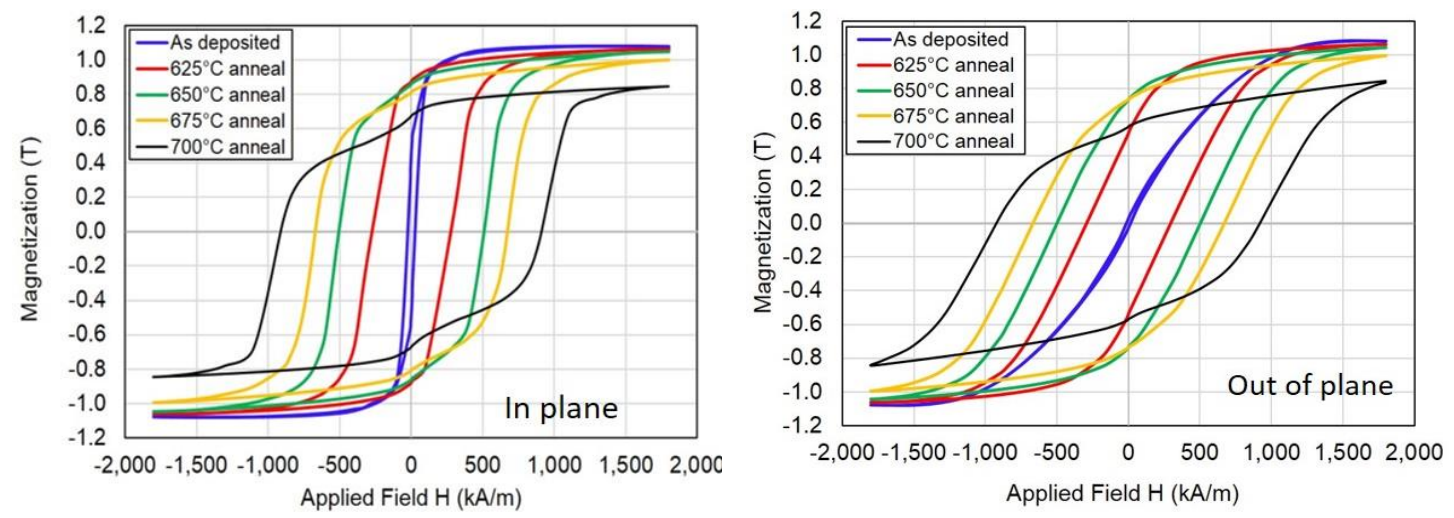

Figure 8: In-plane and out-of-plane magnetization curve of CoPt samples annealed at different temperatures. 


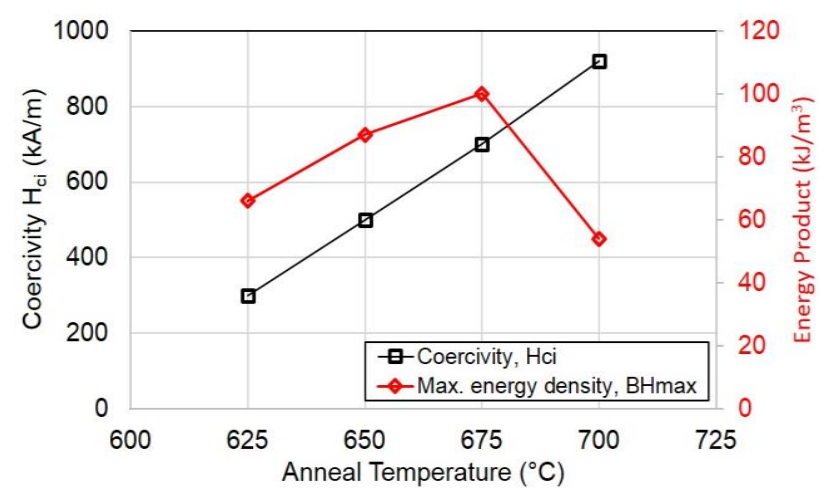

Figure 9: Coercivity and energy product of CoPt samples vs. anneal temperature.
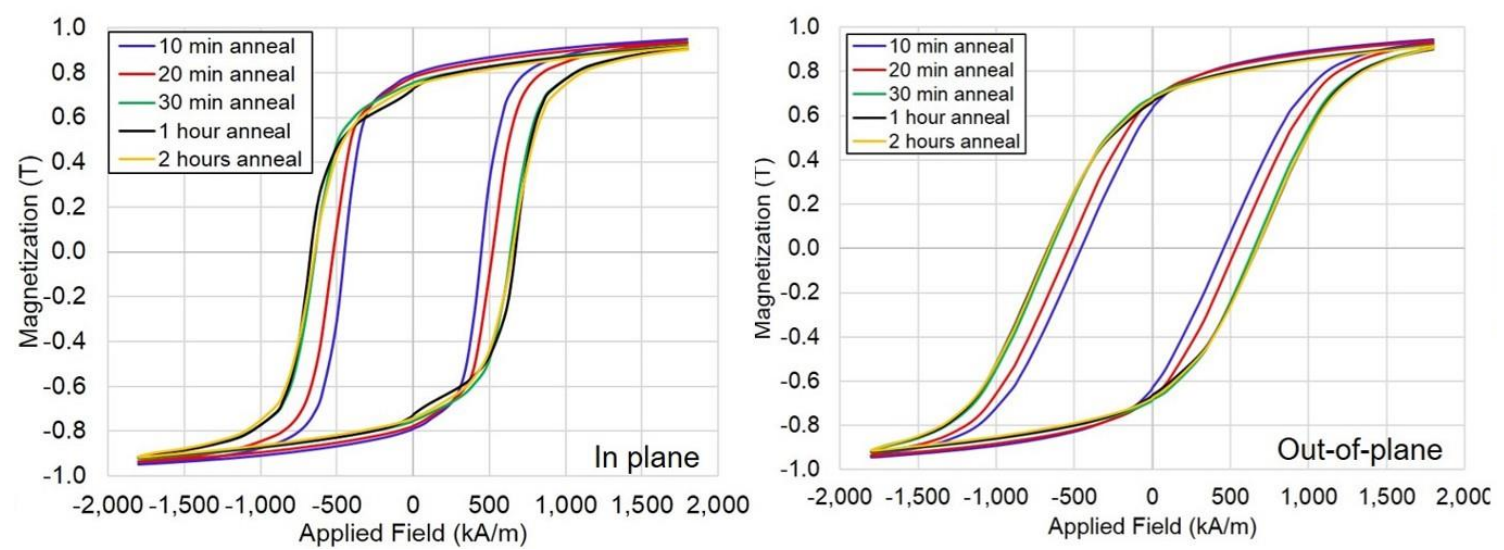

Figure 10: In-plane and out-of-plane and magnetic properties of $\mathrm{L} 1_{0} \mathrm{CoPt}$ annealed at $675 \square \mathrm{C}$ for various anneal times.

\section{Conclusions}

The fundamental and technological development of electroplated $\mathrm{L} 1_{0} \mathrm{CoPt}$ thick-film permanent magnets on silicon substrates is presented in this article. Using a citrate-based bath with diammine-dinitro platinum (II) (p-salt) and cobaltous sulfamate salts, CoPt layers are deposited onto $\mathrm{Cu}$ seeds in photolithographically defined molds on silicon substrates. Film thicknesses range from $0.4-6 \mu \mathrm{m}$ in thickness. It is shown that a current density of $100 \mathrm{~mA} / \mathrm{cm}^{2}$ yields a high plating rate $(\sim 6 \mu \mathrm{m} / \mathrm{hr})$ and after post-deposition annealing at $\sim 700^{\circ} \mathrm{C}$, multi-micron-thick crack-free film can be achieved with good substrate adhesion, fine grain size (20-25 nm), low rms surface roughness $(20 \mathrm{~nm})$, and desirable magnetic properties: $\mathrm{H}_{\mathrm{ci}}=900 \mathrm{kA} / \mathrm{m}, \mathrm{B}_{\mathrm{r}}$ up to 0.8 $\mathrm{T}$, energy product $\mathrm{BH}_{\max }$ up to $100 \mathrm{~kJ} / \mathrm{m}^{3}$, and squareness of 0.93 and 0.87 in the in-plane and out-of-plane directions, respectively.

Undesirable interfacial reactions are identified between the electroplated $\mathrm{L} 1_{0} \mathrm{CoPt}$ magnets and the silicon substrates, which occur during the post-deposition annealing. These reactions lead to a reduction in the extrinsic magnetic properties, especially for films with thickness below $3 \mu \mathrm{m}$. A TiN diffusion barrier layer can be used to prevent silicide reactions between the magnetic layer and silicon substrate, but diffusion of the $\mathrm{Cu}$ seed layer-known to be fast diffuser-into the CoPt layer can still inhibit the magnetic performance of thin layers. These results motivate exploration of alternative seed layers as future work. 
Investigation of structure/property relationships of these thick films show that desirable magnetic properties (high coercivity, high squareness) strongly correlate with high volume fraction of the $\mathrm{L} 1_{0}$ phase. This is attributed to the strong magnetocrystalline anisotropy of the $\mathrm{L} 1_{0}$ phase, and confirms previous observations in thinner CoPt films. For fabrication of electroplated films, the important ramification is to ensure deposition of layers for 50:50 CoPt elemental composition, and then maximizing the conversion from the $\mathrm{A} 1$ to $\mathrm{L}_{0}$ phase by annealing while mitigating interference from the underlying seed layers and substrate. The studies here suggest process conditions of $100 \mathrm{~mA} / \mathrm{cm}^{2}$ current density, $\mathrm{pH}$ of 7 , and post-deposition anneal at $675^{\circ} \mathrm{C}$ for 30 min in forming gas $\left(4 \% \mathrm{H}_{2}, 96 \% \mathrm{~N}_{2}\right)$.

These results indicate that electroplated thick-film $\mathrm{L} 1_{0} \mathrm{CoPt}$ alloys materials are strong candidate materials for wafer-level integration into magnetic microsystems.

\section{Acknowledgement}

This work was supported in part by the U.S. Army Research Office (W911NF-09-1-0511) and DARPA (N6601-11-1-4198). The authors would also like to thank the technical staff of the University of Florida Nanoscale Research Facility and Major Analytical Instrumentation Center for their assistance with microfabrication and material analyses.

\section{References}

[1] T.-S. Chin, "Permanent magnet films for applications in microelectromechanical systems," J. Magn. Magn. Mater., vol. 209, no. 1-3, pp. 75-79, Feb. 2000.

[2] D. P. Arnold and N. Wang, "Permanent Magnets for MEMS," J. Microelectromech. Syst., vol. 18, no. 6, pp. 1255-1266, Dec. 2009.

[3] N. M. Dempsey, "Hard Magnetic Materials for MEMS Applications," in Nanoscale Magnetic Materials and Applications, J. P. Liu, E. Fullerton, O. Gutfleisch, and D. J. Sellmyer, Eds. Springer, 2009, pp. 661-680.

[4] N. M. Dempsey, A. Walther, F. May, D. Givord, K. Khlopkov, and O. Gutfleisch, "High performance hard magnetic $\mathrm{NdFeB}$ thick films for integration into micro-electro-mechanical systems," Appl. Phys. Lett., vol. 90, no. 9, p. 092509, Mar. 2007.

[5] J. M. D. Coey, Magnetism and Magnetic Materials. Cambridge University Press.

[6] K. Ž. Rožman, J. Kovač, P. J. McGuiness, Z. Samardžija, B. Markoli, and S. Kobe, "Microstructural, compositional and magnetic characterization of electrodeposited and annealed Co-Pt-based thin films," Thin Solid Films, vol. 518, no. 6, pp. 1751-1755, Jan. 2010.

[7] T. S. Eagleton, J. Mallet, X. Cheng, J. Wang, C.-L. Chien, and P. C. Searson, "Electrodeposition of $\mathrm{Co}_{\mathrm{x}} \mathrm{Pt}_{1-\mathrm{x}}$ Thin Films," J. Electrochem. Soc., vol. 152, no. 1, p. C27, Jan. 2005.

[8] Y. Sui, L. Yue, R. Skomski, X. Z. Li, J. Zhou, and D. J. Sellmyer, "CoPt hard magnetic nanoparticle films synthesized by high temperature chemical reduction," J. Appl. Phys., vol. 93, no. 10, p. 7571, May 2003.

[9] T. Aoyama, S. Okawa, K. Hattori, H. Hatate, Y. Wada, K. Uchiyama, T. Kagotani, H. Nishio, and I. Sato, "Fabrication and magnetic properties of CoPt perpendicular patterned media," J. Magn. Magn. Mater., vol. 235, no. 1-3, pp. 174-178, Oct. 2001.

[10] H. Zeng, M. L. Yan, N. Powers, and D. J. Sellmyer, "Orientation-controlled nonepitaxial L1 $1_{0}$ CoPt and FePt films," Appl. Phys. Lett., vol. 80, no. 13, p. 2350, Mar. 2002.

[11] M. E. McHenry and D. E. Laughlin, "Growth and characterization of $\mathrm{L}_{0} \mathrm{FePt}$ and $\mathrm{CoPt}$ [001] textured polycrystalline thin films," IEEE Trans. Magn., vol. 37, no. 4, pp. 1309-1311, Jul. 2001. 
[12] O. Kitakami, Y. Shimada, K. Oikawa, H. Daimon, and K. Fukamichi, "Low-temperature ordering of $\mathrm{L}_{1}-\mathrm{CoPt}$ thin films promoted by $\mathrm{Sn}, \mathrm{Pb}, \mathrm{Sb}$, and $\mathrm{Bi}$ additives," Appl. Phys. Lett., vol. 78, no. 8, p. 1104, Feb. 2001.

[13] S. Jeong, Y.-N. Hsu, M. E. Mchenry, and D. E. Laughlin, "Structure and magnetic properties of $\mathrm{L1}_{0} \mathrm{CoPt}(\mathrm{Ag} / \mathrm{MgO}, \mathrm{MgO})$ thin films," J. Appl. Phys., vol. 87, no. 9, pp. 214-216, May 2000.

[14] L. Reichel, S. Fa $\square$ hler, L. Schultz, and K. Leistner, "Initial preorder as condition for $\mathrm{L} 1_{0}$ ordering in ultrathin CoPt films," J. Appl. Phys., vol. 114, no. 9, p. 093909, Sep. 2013.

[15] D. E. Laughlin, K. Srinivasan, M. Tanase, and L. Wang, "Crystallographic aspects of $\mathrm{L}_{0}$ magnetic materials," Scr. Mater., vol. 53, no. 4, pp. 383-388, Aug. 2005.

[16] F. Wang, K. Hosoiri, S. Doi, N. Okamoto, T. Kuzushima, T. Totsuka, and T. Watanabe, "Nanostructured L10 Co-Pt thin films by an electrodeposition process," Electrochem. Commun., vol. 6, no. 11, pp. 1149-1152, Nov. 2004.

[17] O. Berkh, Y. Rosenberg, Y. Shacham-Diamand, and E. Gileadi, "Electrodeposited nearequiatomic CoPt thick films," Electrochem. Solid-State Lett., vol. 11, no. 4, p. D38, Apr. 2008.

[18] E. Gileadi, O. Berkh, and Y. Shacham-Diamand, "Time Effects in the Electrodeposition of CoPt Magnetic Alloys," Electrochem. Solid-State Lett., vol. 12, pp. D53-D56, 2009.

[19] P. L. Wu, X. H. Li, W. Li, H. Y. Sun, Y. Chen, and X. Y. Zhang, "Microstructure and magnetic behavior of electrodeposited CoPt thick films upon annealing," Mater. Lett., vol. 62, no. 2, pp. 309-312, Jan. 2008.

[20] F. M. F. Rhen, E. Backen, and J. M. D. Coey, "Thick-film permanent magnets by membrane electrodeposition," J. Appl. Phys., vol. 97, no. 11, p. 113908, 2005.

[21] T. Ouchi, Y. Arikawa, and T. Homma, "Fabrication of CoPt magnetic nanodot arrays by electrodeposition process," J. Magn. Magn. Mater., vol. 320, no. 22, pp. 3104-3107, Nov. 2008.

[22] N. Yasui, A. Imada, and T. Den, "Electrodeposition of (001) oriented CoPt L1 $1_{0}$ columns into anodic alumina films," Appl. Phys. Lett., vol. 83, no. 16, pp. 3347-3349, Oct. 2003.

[23] H. H. Lou and Y. Huang, "Electroplating," Encyclopedia of Chemical Processing. Taylor \& Francis, pp. 1-10, 2006.

[24] W. Ruythooren, K. Attenborough, S. S Beerten, P. P Merken, J. Fransaer, E. Beyne, C. Van Hoof, J. De Boeck, and J. P. Celis, "Electrodeposition for the synthesis of microsystems," $J$. Micromech. Microeng., vol. 10, pp. 101-107, 2000.

[25] O. D. Oniku, B. Qi, and D. P. Arnold, "Electroplated $\mathrm{L}_{0}$ CoPt thick-film permanent magnets," J. Appl. Phys., vol. 115, no. 17, p. 17E521, May 2014.

[26] J. G. Ibanez, I. Gonzalez, and M. A. Cardenas, "The effect of complex formation upon the redox potentials of metallic ions: Cyclic voltammetry experiments," J. Chem. Educ., vol. 65, no. 2 , p. 173, Feb. 1988.

[27] J. Helsen, "Effect of complexing agents on oxidation potentials," J. Chem. Educ., vol. 45, no. 8, p. 518, Aug. 1968.

[28] N. Teshima, H. Katsumata, and T. Kawashima, "Development of novel redox systems by use of ligand and its application to potentiometry," Anal. Sci., vol. 16, pp. 901-911, 2000.

[29] K. Barmak, J. Kim, L. H. Lewis, K. R. Coffey, M. F. Toney, A. J. Kellock, and J.-U. Thiele, "On the relationship of magnetocrystalline anisotropy and stoichiometry in epitaxial $\mathrm{L} 1_{0}$ CoPt (001) and FePt (001) thin films," J. Appl. Phys., vol. 98, no. 3, p. 033904, Aug. 2005.

[30] M. Birkholz, Thin Film Analysis by X-Ray Scattering. Weinheim, FRG: Wiley-VCH Verlag GmbH \& Co. KGaA, 2005

[31] A. S. Darling, "Cobalt Platinum Alloys-A Critical Review of their Constitution and Properties," Platinum Metals Rev., 1963. [Online]. Available: http://www.docstoc.com/docs/160242420/Cobalt-Platinum-Alloys-Platinum-Metals-Review. [Accessed: 05-Mar-2015]. 
[32] A. Cros, M. O. Aboelfotoh, and K. N. Tu, "Formation, oxidation, electronic, and electrical properties of copper silicides," J. Appl. Phys., vol. 67, no. 7, p. 3328, Apr. 1990.

[33] N. Benouattas, A. Mosser, and A. Bouabellou, "Surface morphology and reaction at $\mathrm{Cu} / \mathrm{Si}$ interface-Effect of native silicon suboxide," Appl. Surf. Sci., vol. 252, no. 20, pp. 75727577, Aug. 2006. 